\title{
DESLOCAMENTOS PENDULARES NA REGIÃO \\ METROPOLITANA DE LONDRINA - PR: uma aproximação
}

\section{COMMUTING IN THE METROPOLITAN REGION OF \\ LONDRINA -PR: an approximation}

\author{
Tânia Maria Fresca \\ Universidade Estadual de Londrina \\ tania_geografia@yahoo.com.br
}

\begin{abstract}
Resumo
Os deslocamentos pendulares continuam a ser temática importante ao estudo das regiões metropolitanas no Brasil, principalmente para aquelas criadas recentemente, onde o conhecimento e análise da dinâmica econômica e social ainda são pouco presentes. Assim, o trabalho apresenta uma aproximação à compreensão desses deslocamentos para a Região Metropolitana de Londrina com base em dados primários, correlacionando os fluxos populacionais às atividades econômicas presentes nos municípios integrantes desta região, acrescidos de Apucarana e Arapongas em razão das importantes ligações que os mesmos apresentam com cidades da região, como uma perspectiva de entendimentos das mesmas.
\end{abstract}

Palavras-Chave: deslocamentos pendulares, região metropolitana de Londrina, atividades econômicas.

\begin{abstract}
The commuting continue to be thematic important to the study of the areas metropolitans in Brazil, especially for those newly created, where the knowledge and analysis of the economic and social dynamics are still restricted. Thus, the work presents an approach to the understanding of these commuting in the Metropolitan Region of Londrina on the primary of given, correlating the population flows to the economic activities gifts in the integrant cities of this region, increased of Apucarana and Arapongas in reason of the important connection that the present with cities of the area, as a perspective of the understanding the same.
\end{abstract}

Keywords: commuting, metropolitan area of Londrina, economic activities.

\section{Introdução}

O objetivo do trabalho é discutir aspectos do processo de deslocamentos pendulares estabelecidos entre os municípios integrantes da Região Metropolitana de Londrina RML, incluindo os municípios de Arapongas e Apucarana, como um percurso ao 
entendimento da complexidade da formação, consolidação e dinâmica espacial desta área. A inserção de Arapongas e Apucarana, se dá em razão dos intensos fluxos populacionais entre esses e também em relação ao município de Rolândia, este último integrante da Região Metropolitana de Londrina. Assim, configura-se a manifestação de deslocamentos pendulares entre os municípios da RML e outros, não pertencentes a essa região.

Contudo, trata-se em realidade, de uma primeira aproximação ao estudo, tendo por base os dados de 2000 (IBGE, 2000) e levantamentos de dados primários para o ano de 2010, que demonstram fluxos populacionais com diferentes objetivos tais como estudo, serviços de saúde, trabalho, consumo de bens e outros serviços. Mas, como se trata de um estudo exploratório, não se apresentam dados para o ano de 2010 sobre os deslocamentos ao trabalho e o consumo. No entanto, a análise apresentada expõe indicativos de complexas relações estabelecidas em termos de fluxos, que poderá suscitar outros estudos e análises após a publicação do Censo de 2010.

Há inúmeras bibliografias que discutem os deslocamentos pendulares no contexto das regiões metropolitanas e aglomerações urbanas, envolvendo discussões sobre os aspectos políticos de suas criações; dinâmica do ponto de vista de sua gestão e governança territorial; dos problemas de habitação, mobilidade e acessibilidade urbana; o processo de segregação residencial e mercado imobiliário; transformações na economia das cidades; os deslocamentos pendulares circunscritos aos municípios que a conformam, dentre outros. É exatamente este último aspecto que frequentemente ocorrem para além da região metropolitana institucionalizada, envolvendo processos de múltiplas ordens e denotando uma amplitude de articulação materiais e imateriais que não se circunscrevem aos limites institucionais. É o que se verá no presente trabalho, onde os fluxos populacionais diários são estabelecidos para além dos municípios da RML, indicando uma intensa divisão social do trabalho, vinculada à oferta de empregos, serviços, comércio, infraestrutura, dentre outros.

Diante do exposto, defende-se aqui a ideia fundamental de que a RML é mais ampla que a institucionalmente criada, tornando clara a necessidade de estudos que ultrapassem aqueles realizados no âmbito do quadro institucionalmente criado. Caso contrário, dinâmicas econômicas, sociais, ambientais, urbanas, dentre outras, não serão apreendidas.

Geo UERJ - Ano 14, no. 23, v. 1, $1^{\circ}$ semestre de 2012 p. 167-191

ISSN: 1415-7543 E-ISSN: 1981-9021

http://www.e-publicacoes.uerj.br/index.php/geouerj 
Dessa maneira, principia-se o texto com aspectos conceituais sobre deslocamentos pendulares no contexto de regiões metropolitanas, seguido da apresentação dos dados primários de deslocamentos entre os municípios da RML, Arapongas e Apucarana. Por fim, analisa - se processos que permitem indicativos para o entendimento dos mesmos.

\section{Deslocamentos pendulares no contexto de regiões metropolitanas: alguns apontamentos}

Em direção ao entendimento dos deslocamentos pendulares, considera-se necessário ter clareza sobre conceitos como aglomeração, área metropolitana, região metropolitana e as complexas relações que envolvem estes processos.

Inicialmente é preciso considerar que estes termos não foram objeto de ampla discussão no Brasil tendo em vista que os estudos prévios no âmbito do IBGE por intermédio do Grupo de Áreas Metropolitanas - GAM - forneceram elementos para estudos, conceituações, delimitações, dentre outros, para a própria institucionalização das regiões metropolitanas na década de 1970. No entanto, a partir dos anos de 1990, de modo geral, esta discussão foi retomada no país mediante: a) ampliação de estudos discutindo globalização e metrópoles no âmbito internacional, com o intuito de entender os papéis que as metrópoles, na escala mundial, passaram a realizar; b) pelas transformações e expansão do próprio processo de metropolização no Brasil, evidenciando inclusive a formação de outras áreas metropolitanas e aglomerações urbanas no contexto do avanço da urbanização brasileira; c) mudanças na legislação brasileira trazidas pela Constituição de 1988, que delegou aos estados da federação a criação e manutenção das regiões metropolitanas. Este último aspecto gerou ampla discussão e críticas pela institucionalização, sem estudos e critérios claros.

No entanto, é preciso entender alguns aspectos históricos da criação das regiões metropolitanas no Brasil e os conceitos subjacentes aos mesmos. EUA e França são dois

países a partir dos quais critérios diversos foram estabelecidos para a delimitação e entendimento de áreas metropolitanas e serviram de base para os estudos brasileiros.

Nos EUA a preocupação com sistemas de coleta de dados estatísticos para as grandes cidades e metrópoles vem desde o começo do século XX, mas foi na década de 1950 que se estabeleceu a Standard Metropolitan Areas - SMA's - baseadas na população da 
cidade principal com pelo menos 50 mil habitantes e a integração econômica e social entre elas, dada pelos deslocamentos diários dos trabalhadores. Mas foi nos anos de 1960, segundo Berry e Horton (1970) que se realizou revisão dos conceitos do SMA's e criou-se a Standard Metropolitan Statistical Area - SMSA - baseado em: a cidade principal deve ter 50 mil habitantes ou mais; a área metropolitana com mais de 100 mil habitantes; mais de $75 \%$ da população atuando em atividades urbanas; a integração entre as cidades da área metropolitana com a principal a partir dos deslocamentos para o trabalho, ter índice de 15\% sobre a população (BERRY; HORTON, 1970, p. 252). Sucessivamente ocorreram mudanças nos critérios e índices utilizados, cujos resultados não foram satisfatórios. Em 2003 nos EUA havia 363 SMA's, sendo a densidade populacional, os deslocamentos diários para o trabalho e o limite mínimo da área metropolitana com 100 mil habitantes, os critérios adotados.

O percentual dos deslocamentos diários foi modificado, elevando-se para $25 \%$, permanecendo até os dias atuais (FITZSIMMONS; RATICLIFFE, 2010). Assim, a região metropolitana padrão nos EUA ainda tem como conceito subjacente uma cidade principal com grande população em conjunto com as cidades adjacentes, que apresentam elevado grau de integração econômica e social com a cidade principal. $\mathrm{O}$ conceito de área metropolitana tem ligação direta com o conceito de integração funcional na determinação de sua extensão. Isto porque os critérios utilizados estão apoiados em dados populacionais e nas ligações entre as cidades, estabelecidas pelas migrações diárias para o trabalho. Embora em cada censo tenha havido revisões nos critérios para o estabelecimento do SMA, até o final dos anos 2000 continuavam os mesmos (FITZSIMMONS; RATICLIFFE, 2010).

No caso francês, a discussão sobre as metrópoles ocorreu a partir dos anos de 1960/70, mas o foco principal era encontrar alternativas à excessiva concentração das atividades e população em Paris. Emergiu a política do aménagement du territoire como caminho para criar novos pólos de desenvolvimento e a implantação governamental de programas para metrópoles de equilíbrio (ROCHEFORT, 1998).

Mas foi a partir da influência norteamericana que ocorreu a realização dos principais estudos do IBGE para a identificação e definição de regiões metropolitanas. Tais estudos realizados pelo Grupo de Áreas Metropolitanas, cujo primeiro texto publicado 
em 1969 (GALVÃO et al., 1969), permite entender os critérios e variáveis utilizadas. Estas foram apoiadas nas:

I- Características demográficas: 1) a cidade principal deve ter uma população de pelo menos 400 mil habitantes; 2) a densidade da população do distrito sede da cidade central deve ser de 500 habitantes por $\mathrm{Km} 2$; 3) a densidade de população dos municípios vizinhos deve ser no mínimo de 60 habitantes por Km2 . Quando o município não possuir tal densidade deverá apresentá-la pelo menos em um distrito que seja contíguo a outro município da área; 4) a variação da população no período 1950/1960 deve ser no mínimo de 45\%, no município ou em um distrito contíguo [...] II - Características estruturais: um município será incluído na área de pesquisa: 1) quando tiver pelo menos $10 \%$ de sua população potencialmente ativa ocupada em atividades industriais; 2) no caso dos chamados núcleos 'dormitórios' esta percentagem deve ser substituída por um índice de movimento pendular, igual ou superior a $20 \%$ da população, deslocando-se diariamente para qualquer ponto da área; 3 ) quando o valor da produção industrial for 3 vezes maior que o da agrícola. III Características de integração: um município será incluído na área de pesquisa: 1) quando tiver pelo menos $10 \%$ de sua população total deslocando-se diariamente, em viagens intermunicipais, para o município que contém a cidade central ou outros municípios da área. $\mathrm{O}$ critério poderá ser aplicado apenas à população urbana do distrito sede ou distrito contíguo a outro município da área; 2) quando tiver um índice de ligações telefônicas para a cidade central superior a 80, por aparelho, durante um ano (GALVÃO, et al., 1969, p. 60-61).

Os autores deixam claro, a importância de todos os critérios, mas ressaltam a força do crescimento demográfico - crescimento vegetativo e migrações - e dos fatores de integração, principalmente os deslocamentos pendulares, como fundamentais para a definição das áreas metropolitanas (GALVÃO et al., 1969, p. 63). Desta forma explicitam que metrópole é "[...] antes de mais nada, uma grande cidade, em termos de volume populacional [...] é também uma grande cidade, por suas funções urbanas bastante diversificadas e especializadas" (GALVÃO et al., 1969, p. 55). Destaca-se, o contingente populacional afim de que haja a emergência de características metropolitanas via diversificação funcional em termos de bens e serviços.

A partir de tais concepções, entendem por área metropolitana "[...] o conjunto de municípios integrados econômica e socialmente a uma metrópole, principalmente por dividirem com ela uma estrutura ocupacional e uma forma de organização do espaço característica e por representarem no desenvolvimento do processo, a sua área de expansão próxima ou remota (GALVÃO et al., 1969, p. 55-56).

É deste conceito que deriva a análise da área metropolitana a partir das relações da cidade principal com a vida nacional e regional do ponto de vista funcional e econômico

Geo UERJ - Ano 14, no. 23, v. 1, $1^{\circ}$ semestre de 2012 p. 167-191

ISSN: 1415-7543 E-ISSN: 1981-9021

http://www.e-publicacoes.uerj.br/index.php/geouerj 
e das relações intra-metropolitanas. Nesta perspectiva analítica emerge para os autores a noção de região metropolitana, que inclui além da área metropolitana supra citada "[...] uma faixa periférica que tende a ser metropolitana em uma ou duas décadas" (GALVÃO et al., 1969, p. 57-58). Em outras palavras, a região metropolitana envolve a área metropolitana e cidades que podem ser incorporadas ao processo de metropolização. Portanto, uma área mais ampla, ligada ao avanço do sistema de transporte urbano, podendo estender-se por muitos quilômetros e sobre a qual o governo deve estar atento no sentido de prever e ofertar serviços comuns e infraestrutura.

No entanto, quando relações de integração através de deslocamentos cotidianos para o trabalho, consumo, estudo, etc. ocorrer entre uma cidade principal e núcleos urbanos conurbados ou não à primeira, tem-se a aglomeração urbana. Esta

[...] expressão é reservada para cidades já de um certo tamanho e com uma
localização relativamente independente em relação a outros grandes sítios
urbanos.[... O conjunto forma uma unidade de construções e de espaço
econômico, mas que pode muito bem ser repartida por uma série, um grande
número de unidades administrativas. A cidade-centro exerce um certo efeito
de atração: é em relação a ela que se organiza a rede convergente de
transportes; é ela o lugar de concentração de empregos. Os bairros da cidade,
assim como os setores dos arredores periféricos, podem ter características
diferentes, quer do ponto de vista da morfologia, quer da repartição das
atividades e do nível social (BEAUJEAU-GARNIER, 1983, p. 135-136).

A aglomeração assim colocada já está vinculada à presença de uma cidade principal, de certo tamanho populacional e diversidade de atividades urbanas mais complexas. Compreende ainda uma área de ocupação urbana contínua ou não, envolvendo várias cidades, entre as quais ocorrem fluxos diversos ligados aos fatores de integração econômica e social, bem como complementaridade funcional (RIBEIRO, 2009). A partir destes conceitos e elementos foram estabelecidas as primeiras regiões metropolitanas no Brasil.

Daquele momento até o presente, inúmeras mudanças ocorreram diante de transformações e continuidade do processo de metropolização no Brasil, no qual incluise a formação de novas metrópoles e aglomerações urbanas, com intensificação dos deslocamentos pendulares conforme apontam trabalhos de Oliveira; Oliveira (2011), Antico (2004), Baeninger, Ojima (2008), Ervatti, Jardim (2006), Moura, Branco, Firkowsky(2005), dentre outros. 
Do ponto de vista teórico sobre a interpretação destes últimos, também ocorreram avanços, particularmente no tange à qualificação da pessoa que se desloca, além das críticas às interpretações métricas que permitem determinar aspectos como proporcionalidade, equivalência, similaridade, mas, não dão conta da realidade porque exclui outras dimensões do cotidiano (JARDIM, 2011). Tratam-se de críticas às abordagens neoclássica e estruturalista e ao mesmo tempo a busca por novos aportes para entendimento dos mesmos, conforme pode ser verificado na análise de Oliveira (2011).

Desta maneira, os deslocamentos pendulares configuram-se em uma das "[...] dimensões dos processos de deslocamento da população no território, num contexto determinado e socialmente constituída, no tempo e no espaço" (JARDIM, 2011, p.58). Exatamente por ser historicamente determinado, um primeiro aspecto ainda a ser considerado é o fato de que o trabalho continua a ter centralidade no ato do deslocamento cotidiano, principalmente quando se considera a taxa de desemprego no país, impondo entre outros, o deslocamento para garantir condições de sobrevivência, ou como colocam Jardim e Ervatti (2006, p. 2), que estes estão relacionados à produção da existência, entendida como "[...] condições de vida da população, de seus custos vitais medidos pela análise das condições ambientais, de trabalho, de saúde e educação, do uso do tempo social [...] relacionados à vida social”. Um segundo aspecto que continua fundamental é o fato de que estes deslocamentos são um processo social e devem assumir a dimensão de classes sociais (SINGER, 1985, p. 52), pois caso contrário, ter-se-ia uma análise apenas do indivíduo.

Mas os deslocamentos não se realizam apenas para trabalho e estudo, porque envolvem a busca por outros serviços, além do consumo, que se amplia. Da mesma maneira, a análise deve considerar aspectos como o percurso entre moradia e lugar de trabalho em termos de tempo e espaço, aspectos da vida cotidiana como frequência, duração, distância, formas de deslocamento, e acima de tudo, as motivações para os deslocamentos (JARDIM, 2011). No que tange a este último aspecto, não se trata mais de compreender a tomada de decisão como ato individual, porque incorpora família, comunidade, redes sociais, aspectos culturais, dentre outros (OLIVEIRA, 2011). Mas cabe apontar que os deslocamentos articulam-se também ao movimento da economia e da sociedade: ora expansiva criando maior oferta de emprego e salário, ampliando os 
deslocamentos para determinados municípios seja para trabalho, consumo de bens e serviços; ora recessiva com implicações diretas nos fluxos cotidianos.

E no contexto das regiões metropolitanas e aglomerações urbanas brasileiras, estes fluxos foram muito ampliados nas últimas décadas, impondo que seu estudo também coloque em relevo questões de infraestruturas como transporte intraurbano, metropolitano, individual, a extensão da área e da região e todas as implicações que isto possa gerar, particularmente a questão da segregação (MOURA, BRANCO, FIRKOWSKY, 2005).

Dessa maneira, pode-se retomar o início da presente discussão sobre a importância, nos dias atuais, destes fluxos para a compreensão das dinâmicas econômica, social e espacial de regiões metropolitanas. Em outras palavras, os deslocamentos pendulares para trabalho e estudo continuam a ser aspecto dos mais significativos, mas a eles se incorporam outros deslocamentos para atividades como consumo de bens e serviços que se realizam cotidianamente. Se no final da década de 1960 já se argumentava a articulação entre deslocamentos pendulares como elemento para entendimento da dinâmica de regiões metropolitanas, no momento atual essas correlações continuam válidas. É necessário ter em conta outros aspectos como as profundas alterações econômicas e sociais que ocorreram no país desde os anos de 1980, que dentre outras, implicaram em: ampliação e transferência da produção industrial para diferentes áreas do país, mas com tendência à maior presença nas maiores cidades, aglomerações urbanas e novas metrópoles; ampliação e diversificação da oferta de bens e oferta de serviços com ampliação do consumo; em fortes modificações na distribuição ocupacional dos trabalhadores, com tendência a ampliação daqueles no setor terciário; ampliação do sistema de transporte, particularmente o metropolitano e individual; ampliação da área ocupada pelas aglomerações e regiões metropolitanas, dentre outras.

\section{Região metropolitana de Londrina e deslocamentos pendulares: para além da região}

A Região Metropolitana de Londrina - RML - foi criada em junho de 1998 sendo formada pelos municípios de Cambé, Jataizinho, Ibiporã, Londrina, Rolândia e Tamarana. Posteriormente foram inclusos os municípios de Bela Vista do Paraíso em

Geo UERJ - Ano 14, nº. 23, v. 1, $1^{\circ}$ semestre de 2012 p. 167-191

ISSN: 1415-7543 E-ISSN: 1981-9021

http://www.e-publicacoes.uerj.br/index.php/geouerj 
2000, Sertanópolis em 2002, Primeiro de Maio, Alvorada do Sul e Assaí em 2010; em abril de 2012 foram inclusos os municípios de Sabáudia, Pitangueiras e Jaguapitã. A inclusão de outros municípios na RML, atende diversos interesses políticos, principalmente no âmbito dos deputados estaduais que procuram ampliar suas bases eleitorais, na medida em que a inclusão dos mesmos na RML, permite a obtenção de maiores recursos para habitação, educação, saúde, infraestrutura, dentre outros.

Criada em 1998, somente em 2007 o governo estadual estabeleceu as condições para a instalação da Coordenadoria da Região Metropolitana de Londrina - Comel - mas os resultados de sua atuação ainda são parcos, já que o governo, desde sua instalação, não fez a efetiva dotação orçamentária, exceto aqueles projetos que estão em curso mediante recursos federais oriundos do Programa de Aceleração do Crescimento PAC.

Enquanto processo político, esta institucionalização não levou em conta diversos aspectos do ponto de vista da dinâmica interurbana que ocorre entre cidades que a compõem e aquelas não inseridas na mesma. Dessa forma, as regiões metropolitanas institucionalmente criadas:

[...] têm como pontos em comum, dois elementos essenciais: a) são formados por mais de um município, com o município núcleo - que lhes dá o nome representando uma área bem maior que as demais; b) são objeto de programas especiais, levados adiante por organismos regionais especialmente criados, com a utilização de normas e recursos em boa parte federais. São, na verdade, regiões de planejamento (SANTOS, 1993, p. 84).

Esta região pode ser visualizada no mapa 01, permitindo verificar a localização das cidades, chamando a atenção para aquelas que estão ao norte e ao sul de Londrina, com distancias médias oscilando em torno de 40 a $60 \mathrm{Km}$. Observa-se que ao longo da rodovia BR 369, tem-se uma aglomeração urbana entre Londrina, Cambé, Ibiporã, Rolândia e Jataizinho.

Geo UERJ - Ano 14, no. 23, v. 1, $1^{\circ}$ semestre de 2012 p. 167-191

ISSN: 1415-7543 E-ISSN: 1981-9021

http://www.e-publicacoes.uerj.br/index.php/geouerj 


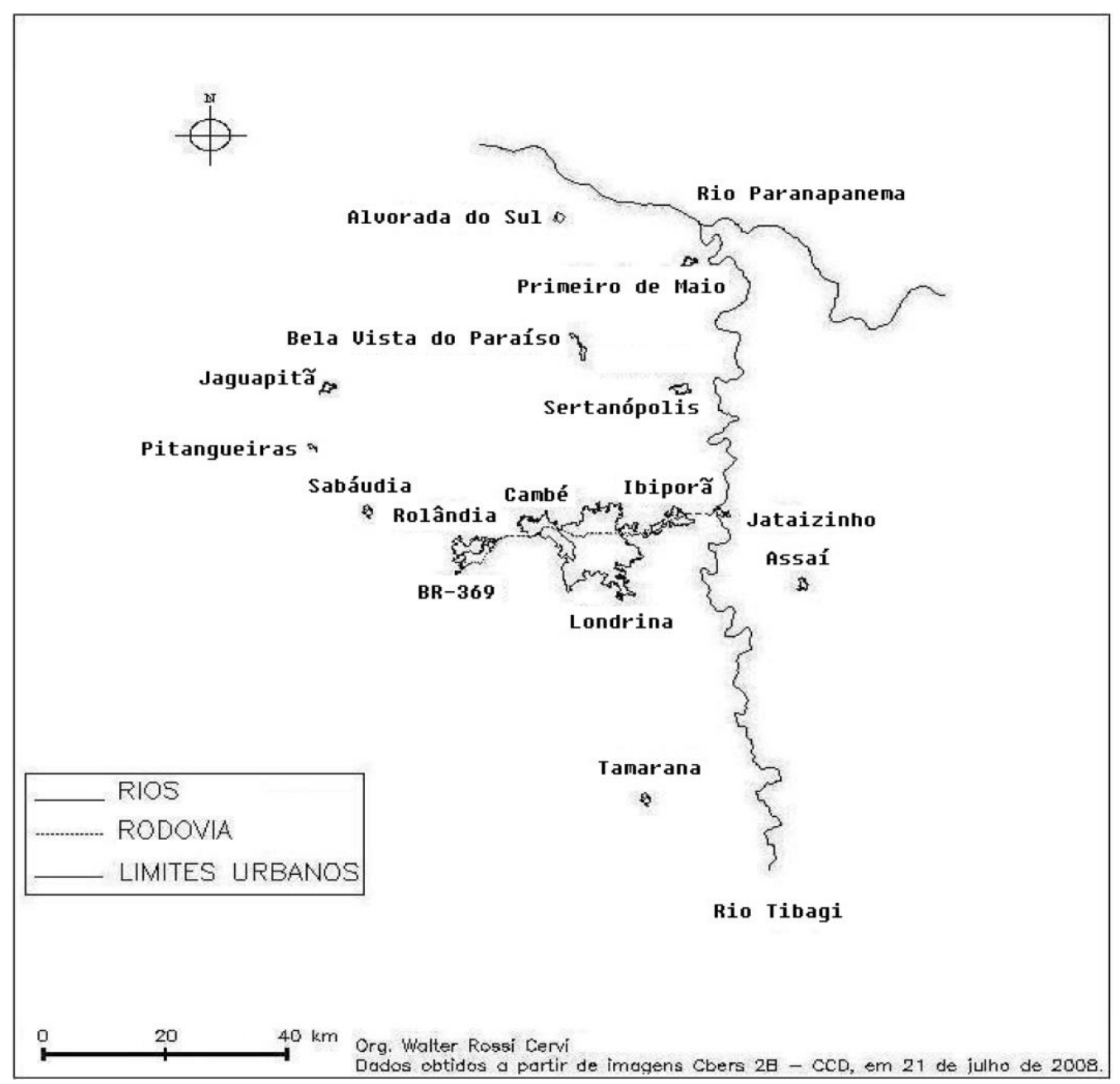

Mapa 01: Localização dos Municípios que Integram a Região Metropolitana de Londrina, 2012.

A evolução desta aglomeração urbana na RML, segundo Fresca (2011), foi principiada na década de 1970, entre Londrina e Cambé, a partir de duas áreas urbanas resultantes de uma expansão separada e distante da cidade de Cambé, que avançava sentido leste, em direção à Londrina. Ao longo dos anos de 1980, a ocupação avançou em ambas cidades, não permitindo distinção de limites entre Cambé e Londrina, enquanto as demais continuavam individualizadas. O mesmo processo ocorreu nos anos de 1990, com diferenças em relação à expansão da malha urbana de cada uma das cidades localizadas ao longo da BR 369. Uma década depois, verificou-se importante crescimento da área urbana de Rolândia e Ibiporã, ambas em direção à Cambé e Londrina respectivamente. 
Em 2010 a ocupação urbana avançava entre Rolândia, Cambé, Londrina e Ibiporã, enquanto Jataizinho apresentava expansão em direção à Ibiporã. Trata-se de um processo de crescimento territorial, conformando uma grande área urbana ao longo da BR 369. Neste sentido, importa frisar que as demais cidades que compõem a RML em 2012, não apresentavam significativa expansão, mantendo-se ademais com restrita expansão de suas áreas urbanas. Neste conjunto é nítida a presença de uma aglomeração urbana circundada por outros municípios, o que demonstra relativa repetição de um processo já evidenciado no Brasil.

Assim, nesta região se tem os deslocamentos pendulares para trabalho e estudo, apresentados no quadro 1, com os dados para o ano de 2000 (IBGE,2000).

Quadro 1: Deslocamentos para Trabalho e Estudo nos Municípios da Região Metropolitana de Londrina, Arapongas e Apucarana no ano de 2000.

\begin{tabular}{|l|c|c|c|c|c|c|}
\hline Município & Pop. Total & $\begin{array}{l}\text { Não Trab. } \\
\text { nem Estuda }\end{array}$ & $\begin{array}{l}\text { Trab. e } \\
\text { Est. no } \\
\text { Mun. de } \\
\text { Resid. }\end{array}$ & $\begin{array}{l}\text { Trab. e Est. } \\
\text { em outro } \\
\text { Mun. do } \\
\text { Estado }\end{array}$ & $\begin{array}{l}\text { Trab. e } \\
\text { Estud. em } \\
\text { outro } \\
\text { Estado }\end{array}$ & $\begin{array}{l}\text { Trab. e } \\
\text { Estuda } \\
\text { em } \\
\text { outro } \\
\text { País }\end{array}$ \\
\hline Alv. do Sul & 9.253 & 5.750 & 3.003 & 375 & 120 & - \\
\hline Assaí & 18.045 & 10.369 & 6.995 & 561 & 79 & 41 \\
\hline B. V. Paraíso & 15.031 & 8.893 & 5.149 & 682 & 296 & 4 \\
\hline Cambé & 88.186 & 44.814 & 28.727 & 14.253 & 368 & 23 \\
\hline Ibiporã & 42.153 & 22.966 & 14.517 & 4.344 & 309 & 8 \\
\hline Jataizinho & 11.327 & 5.847 & 4.177 & 1.250 & 53 & - \\
\hline Londrina & 447.065 & 301.904 & 136.958 & 5.854 & 1.963 & 386 \\
\hline Prim. Maio & 10.728 & 6.466 & 3.882 & 268 & 111 & - \\
\hline Rolândia & 49.410 & 31.778 & 15.447 & 2.016 & 158 & - \\
\hline Sertanópolis & 15.147 & 9.988 & 4.706 & 355 & 98 & - \\
\hline Tamarana & 9.713 & 5.588 & 3.843 & 259 & 9 & 13 \\
\hline Jaguapitã & 10.932 & 6.788 & 3.742 & 344 & 35 & 23 \\
\hline Pitangueiras & 2.418 & 1.588 & 585 & 144 & 100 & - \\
\hline Sabáudia & 5.413 & 3.519 & 1.704 & 185 & 6 & - \\
\hline Arapongas & 85.428 & 56.499 & 27.214 & 1.378 & 286 & 45 \\
\hline Apucarana & 107.827 & 70.511 & 34.908 & 2.054 & 341 & 12 \\
\hline Fonte: IBGE & 20006 \\
\hline
\end{tabular}

Fonte: IBGE, 2000.

A primeira observação diz respeito ao fato de que em 2000 o número de municípios integrantes da RML era menor, mas foram utilizados dados referentes aos que integram a RML em 2012. Os dados evidenciam deslocamentos bastante diferenciados entre os municípios: desde aqueles com fortes deslocamentos, considerados aqui acima de cinco mil pessoas, até aqueles que são bastante restritos. Assim, tinha-se 2 municípios com fortes deslocamentos: Cambé cujos deslocamentos representavam 16,16\% da população total e Londrina que representava $1,3 \%$ da população total; aqueles entre dois e cinco 
mil deslocamentos, considerados médios, eram representados por Rolândia com 4,08\% sobre o total da população; Ibiporã com 10,30\%; Jataizinho com 11,03\%, Arapongas com $1,61 \%$ e Apucarana com $1,90 \%$. Embora estes representem deslocamentos com números absolutos elevados, em termos relativos o destaque ficou para aqueles que conformam a aglomeração urbana de Londrina. Com menos de mil deslocamentos estavam todos os demais municípios integrantes da RML, e em termos percentuais representavam menos de $5 \%$ da população total. Exceção era Pitangueiras, onde o número de deslocamentos representava $5,95 \%$ do total.

Para o ano de 2010, importa esclarecer que os dados apresentados referem-se ao período dezembro de 2009 a novembro de 2010, o que significa que não havia linhas metropolitanas de transporte para aqueles municípios inclusos posteriormente.

Quadro 2: Fluxo de Passageiros de Linhas Metropolitanas entre cidades da RML e Apucarana-Rolândia: nov. 2009 a dez. 2010: média diária (ida e volta).

\begin{tabular}{|l|l|c|l|l|l|}
\hline \multicolumn{1}{|c|}{ Linhas } & $\begin{array}{l}\text { Total anual } \\
\text { passageiros* }\end{array}$ & $\begin{array}{l}\text { Média diária } \\
\text { passageiros }\end{array}$ & $\%$ Ida & $\%$ Volta & $\begin{array}{l}\text { Ano implantação } \\
\text { linha }\end{array}$ \\
\hline $\begin{array}{l}\text { Cambé- } \\
\text { Ibiporã }\end{array}$ & 3.771 .229 & 15.715 & 49,96 & 50,03 & 1988 \\
\hline $\begin{array}{l}\text { Londrina- } \\
\text { Cambé }\end{array}$ & 3.637 .751 & 15.157 & 48,31 & 51,68 & 1988 \\
\hline $\begin{array}{l}\text { Londrina- } \\
\text { Rolândia }\end{array}$ & 1.122 .372 & 4.676 & 50,18 & 49,82 & 1998 \\
\hline $\begin{array}{l}\text { Londrina- } \\
\text { Jataizinho }\end{array}$ & 742.703 & 3.095 & 51,31 & 48,69 & 1989 \\
\hline $\begin{array}{l}\text { Londrina- } \\
\text { Ibiporã }\end{array}$ & 534.384 & 2.226 & 53,34 & 46,65 & 1988 \\
\hline $\begin{array}{l}\text { Londrina - } \\
\text { Bela Vista do } \\
\text { Paraiso }\end{array}$ & 322.750 & 1.345 & 51,59 & 48,41 & 1999 \\
\hline $\begin{array}{l}\text { Londrina- } \\
\text { Sertanópolis }\end{array}$ & 107.139 & 446 & 55,01 & 44,99 & 2004 \\
\hline $\begin{array}{l}\text { Londrina - } \\
\text { Assaí }\end{array}$ & 63.441 & 264 & 50,62 & 49,38 & 2001 \\
\hline $\begin{array}{l}\text { Londrina- } \\
\text { Tamarana }\end{array}$ & 75.187 & 313 & 49,01 & 50,98 & 2003 \\
\hline $\begin{array}{l}\text { Primeiro de } \\
\text { Maio- } \\
\text { Sertanópolis }\end{array}$ & $\begin{array}{l}\text { (jan- } \\
\text { abr.2011) }\end{array}$ & 321,15 & 51,74 & 48,26 & Jan./2011 \\
\hline $\begin{array}{l}\text { Apucarana- } \\
\text { Rolândia }\end{array}$ & 1.132 .626 & 4.719 & 49,90 & 50,10 & 1998 \\
\hline Somatoria & & & & & \\
\hline
\end{tabular}

* Somatória total de passageiros de todas as linhas entre as cidades.

Fonte: DER-PR (2011).

Org. Fresca, T. Maria. 
Da mesma maneira, os dados referem-se ao total de passageiros de cada uma das linhas metropolitanas obtidas junto às empresas e ao Departamento de Estrada e Rodagens do Paraná (DER - PR, 2011). O primeiro aspecto a considerar são as datas de implantação das linhas de transporte coletivo metropolitano, conforme o quadro 2.

Os dados permitem verificar que as ligações via transporte metropolitano são realizadas desde o final dos anos de 1980, entre as cidades de Londrina, Cambé, Ibiporã e Jataizinho, mas, havia uma linha entre Cambé e Ibiporã, significando deslocamentos que não partiam da cidade principal.

Estas ligações antecederam em uma década a criação da RML, evidenciando a condição precípua de suas instalações: número de passageiros que diariamente realizavam deslocamentos entre as cidades referidas, mas demonstra ainda que as ligações não eram unidirecionais. Havia, portanto, fluxos populacionais entre as cidades de Ibiporã e Cambé, que não partiam da cidade principal, o que é indicativo de intensa divisão social do trabalho. A implantação de outras linhas metropolitanas foi intensificada após 1998 como aquelas entre Londrina e Rolândia e Londrina e Bela Vista do Paraíso.

Neste momento a implantação da linha entre Apucarana/Arapongas - Rolândia, destaca o fato da primeira não estar inclusa na RML e se articular com última, a partir da qual, os passageiros podem deslocar-se para outras cidades da RML.

A partir dos anos de 2000 e de modo a atender as cidades inseridas na região, outras linhas foram criadas conforme o quadro 2 e mapa 2. Do ponto de vista da intensidade dos fluxos populacionais, observa-se que estas linhas não são diretas do ponto de vista das ligações entre as cidades de partida e chegada. Assim, a linha Apucarana-Rolândia, passa por Arapongas; a linha Assaí-Londrina, passa por Jataizinho e Ibiporã antes de chegar a Londrina e a linha Cambé-Ibiporã passa por Londrina. No entanto, em razão da fonte utilizada, não é possível obter os dados por cidade, mas apenas da linha completa. Porém, o mapa evidencia que os deslocamentos pendulares mais importantes ocorrem entre as cidades de Apucarana, Arapongas, Rolândia, Cambé, Londrina, Ibiporã, Bela Vista do Paraíso e Jataizinho.

As demais cidades apresentam fluxos menos intensos de deslocamentos diários, alguns inclusive se realizam mediatizados por outras cidades, como é o caso de Primeiro de Maio - Sertanópolis e Alvorada do Sul - Bela Vista do Paraíso, a partir dos quais podem dirigir-se para Londrina. Chama a atenção os dados destes últimos pelo fato de 
serem muito restritos, enquanto Jataizinho, que mesmo sendo um município com pequena população total e urbana, apresenta elevado número de deslocamentos.

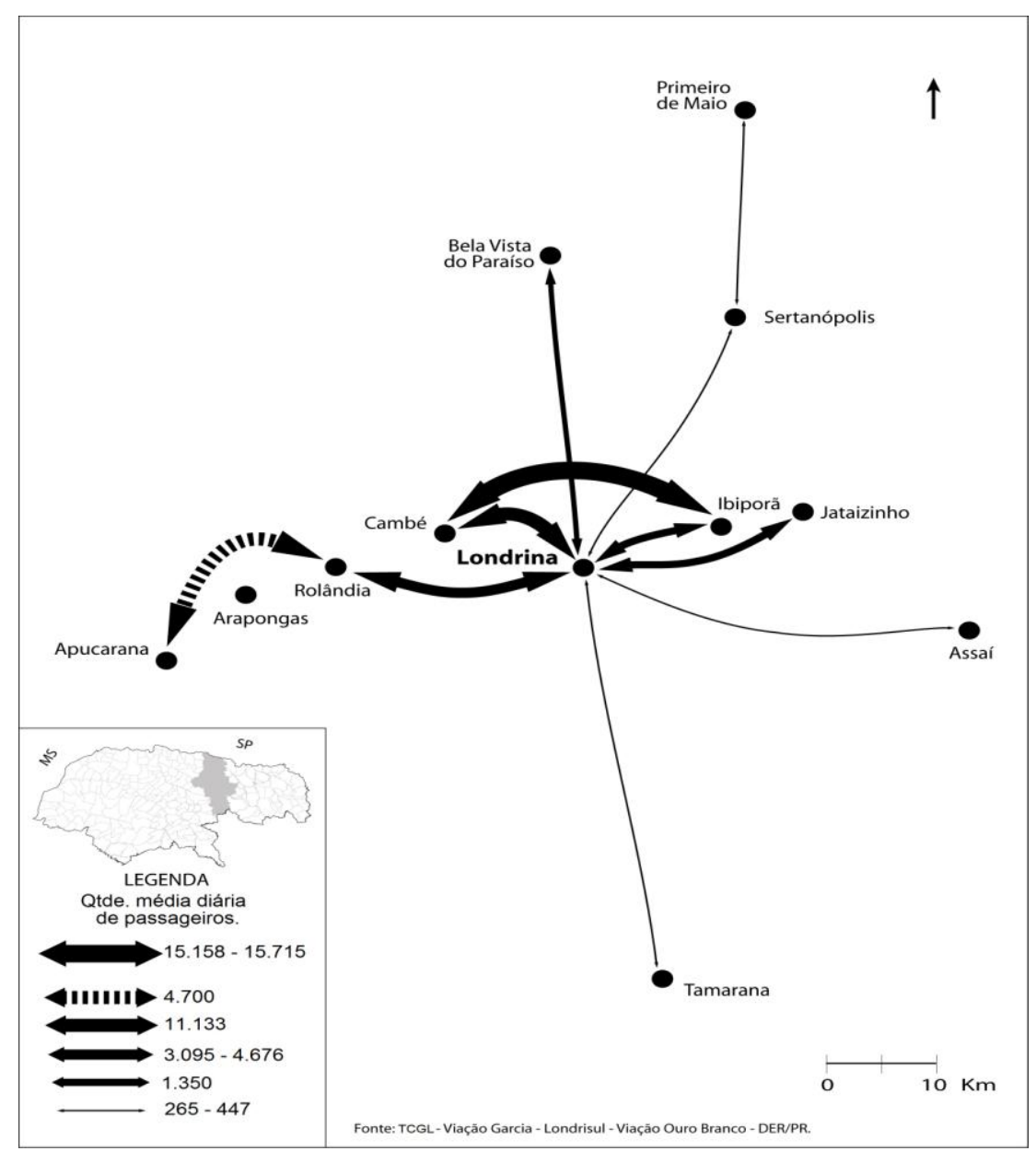

Mapa 2: Fluxos de Passageiros do Transporte Metropolitano na RML e ApucaranaRolândia: dezembro de 2009 a novembro de 2010 (média diária - ida e volta).

Fonte: DER-PR, 2011; TCGL, Londrisul, Viação Ouro Branco, 2011.

A estes dados, deve-se ainda acrescentar aqueles realizados pelas Prefeituras Municipais para transporte na área de saúde e os privados para educação. As cidades integrantes da RML estão inseridas ainda no Consórcio Intermunicipal de Saúde do Médio Paranapanema - Cismepar - com sede em Londrina, cuja função é ofertar serviços médicos e hospitalares de média e elevada complexidade e várias especialidades para as cidades integrantes do consórcio.

Assim, os deslocamentos para obtenção de serviços de saúde em Londrina, tornam-se elevados, diante dos recursos médico-hospitalares presentes na cidade. Os serviços educacionais presentes em Londrina, principalmente o ensino superior, é amplo e 
diversificado diante das instituições presentes. Em Londrina o ensino superior se faz presente desde os anos de 1950 mediante a implantação das Faculdades de Filosofia, Direito, Medicina, dentre outras, criadas a partir da conjugação de interesses locais e estaduais. Estas faculdades foram unificadas com a criação da Universidade Estadual de Londrina em 1971, com ampliação sucessiva de cursos de graduação e pós-graduação. Nos anos de 1970, havia 3 instituições de ensino superior na cidade, enquanto a maior expansão das instituições ocorreu ao longo dos anos de 2000. À exceção da UEL, da UTFPR e Instituto Federal do Paraná - IFRP - em Londrina, todas as demais são privadas. Com relação ao número de alunos, Londrina apresentava aproximadamente 34 mil alunos de graduação e 5.531 de pós-graduação, cujo total representava 8,10\% do total da população urbana da cidade em 2010.

Assim, o quadro 3, fornece os dados sobre deslocamentos pendulares para obtenção de serviços de saúde e educação em Londrina que não estão inclusos nos dados anteriormente apresentados (quadro 1), já que os mesmos são realizados pelas Prefeituras Municipais e por transportes privados.

Quadro 3: Deslocamentos Diários dos Municípios da RML para Londrina para Serviços de Saúde e Educação, set. 2011.

\begin{tabular}{|l|c|c|}
\hline Município & Saúde/dia & Ensino/dia \\
\hline Alv. do Sul & 60 & 85 \\
\hline Sertanópolis & 102 & 196 \\
\hline Rolândia & 18 & 540 \\
\hline Bela V. Paraíso & 18 & 210 \\
\hline Assai & 13 & 276 \\
\hline Jataizinho & 39 & 75 \\
\hline Ibiporã & 25 & 160 \\
\hline Tamarana & 40 & 80 \\
\hline Primeiro de Maio & 55 & 95 \\
\hline Cambé & 60 & 752 \\
\hline Pitangueiras & 3 & 145 \\
\hline Jaguapitã & 11 & \\
\hline
\end{tabular}

Fonte: Levantamento de Campo.

Org.: Fresca, T. M.

Geo UERJ - Ano 14, no. 23, v. 1, $1^{\circ}$ semestre de 2012 p. 167-191

ISSN: 1415-7543 E-ISSN: 1981-9021

http://www.e-publicacoes.uerj.br/index.php/geouerj 
A primeira observação em relação ao quadro é o fato de que Apucarana, Arapongas e Sabáudia estão inseridos na $16^{\mathrm{a}}$ Regional de Saúde, com sede na primeira, integrando vários municípios, envolvendo também outras relações de deslocamentos para obtenção deste serviço através do Consórcio Intermunicipal do Vale do Ivaí e Região - Cisvir.

A segunda observação a ser realizada é sobre os dados dos deslocamentos, que por intermédio dos convênios celebrados entre os municípios e a Cismepar, o número de consultas, exames e outros procedimentos médicos são estabelecidos mediante capacidade de pagamento dos primeiros, significando para muitos, número bastante restrito. Mas, parcela destes municípios também apresenta pequena população total. Uma terceira observação refere-se ao fato de que cidades como Cambé, Rolândia e Ibiporã possuem um sistema de saúde mais amplo que os demais, incluindo-se hospitais públicos e privados e diversas unidades básicas de saúde. A título de exemplo, Ibiporã contava em 2011 com 08 unidades básicas de saúde - UBS -, 01 hospital público, 01 hospital privado, 01 ambulatório com várias especialidades para consultas; Rolândia com 07 UBS das quais 4 urbanas e 03 rurais, 02 hospitais privados e um público, além de ambulatório; Cambé com 11 UBS na área urbana e 01 na rural; 01 hospital privado e 01 público. As demais cidades contam majoritariamente com unidades básicas de saúde e por vezes um pequeno hospital para alguns procedimentos.

Do ponto de vista do ensino, particularmente o superior, os fluxos são maiores que os da saúde, sendo realizados privadamente por ônibus e vans. $\mathrm{O}$ total destes deslocamentos torna-se melhor compreendido quando se verifica a população dos municípios da RML, de Arapongas e Apucarana em 2010, conforme quadro 4. 
Quadro 4: População Total, Urbana e Rural dos Municípios da RML, Arapongas e Apucarana, 2010.

\begin{tabular}{|l|r|r|r|}
\hline Cidade & \multicolumn{1}{l|}{ Total } & \multicolumn{1}{l|}{ Urbana } & \multicolumn{1}{l|}{ Rural } \\
\hline Londrina & 506.645 & 493.457 & 13.188 \\
\hline Cambé & 96.735 & 92.956 & 3.779 \\
\hline Rolândia & 57.870 & 54.758 & 3.112 \\
\hline Ibiporã & 48.200 & 45.896 & 2.304 \\
\hline Jataizinho & 11.859 & 11.037 & 822 \\
\hline Sabáudia & 6.095 & 5.096 & 999 \\
\hline Pitangueiras & 2.814 & 2.040 & 774 \\
\hline Jaguapitã & 12.256 & 10.412 & 1.844 \\
\hline $\begin{array}{l}\text { Bela Vista } \\
\text { do Paraíso }\end{array}$ & 15.080 & 14.198 & 882 \\
\hline Assaí & 16.368 & 13.601 & 2.767 \\
\hline Sertanópolis & 15.637 & 13.716 & 1.921 \\
\hline $\begin{array}{l}\text { Alvorada do } \\
\text { Sul }\end{array}$ & 10.298 & 7.349 & 2.949 \\
\hline $\begin{array}{l}\text { Primeiro de } \\
\text { Maio }\end{array}$ & 10.832 & 10.083 & 749 \\
\hline Tamarana & 12.232 & 5.857 & 6.375 \\
\hline Arapongas & 104.161 & 101.862 & 2.299 \\
\hline Apucarana & 120.884 & 114.104 & 6.780 \\
\hline
\end{tabular}

Fonte: IBGE, 2010.

Org.: Fresca, T. M.

Verifica-se que, a grande maioria dos municípios integrantes da RML, apresenta pequena população total e urbana, dos quais se excetua aqui, Ibiporã e Rolândia não só pela população, mas pela complexidade das atividades urbanas que discutir-se-á a seguir; o município menos urbanizado é Tamarana; a menor sede urbana em termos populacionais é Pitangueiras, enquanto os demais tem elevado índice de urbanização. Assim, os deslocamentos diários para obtenção serviços de saúde em Londrina, apresentam maiores índices para os municípios com menores populações totais, oscilando de 0,11 a $0,65 \%$ da população total e inversamente menores para aqueles com maiores populações.

Isto é correlato aos serviços médicos prestados nestes últimos, impondo menor demanda em Londrina, prioritariamente para especialidades de média e elevada complexidade. Os deslocamentos diários para o ensino superior em Londrina apresentam índices maiores, oscilando de $0,63 \%$ até $1,68 \%$ da população total. 
Contudo, este quadro geral dos deslocamentos pendulares no contexto da RML, de Arapongas e Apucarana, pode ser melhor compreendido na medida em que entender-se o conjunto das atividades econômicas presentes nas cidades envolvidas, particularmente a geração de empregos, conforme quadro 5 a seguir.

Quadro 5: Total de Estabelecimentos e Trabalhadores de Setores Econômicos Selecionados da Região Metropolitana de Londrina, Arapongas e Apucarana, 2010.

\begin{tabular}{|c|c|c|c|c|c|c|c|c|c|c|c|c|}
\hline \multirow[t]{2}{*}{ Municípios } & \multicolumn{2}{|l|}{ Ind. } & \multicolumn{2}{|c|}{ Com. Varej. } & \multicolumn{2}{|c|}{ Com. Atac. } & \multicolumn{2}{|l|}{ Serviços } & \multicolumn{2}{|c|}{$\begin{array}{l}\text { Construção } \\
\text { Civil }\end{array}$} & \multicolumn{2}{|c|}{$\begin{array}{l}\text { Agric, Criac. } \\
\text { Animais, Ext. } \\
\text { veg. e min. }\end{array}$} \\
\hline & Estab. & Trab. & Estab. & Trab. & Estab. & Trab. & Estab. & Trab. & Estab. & Trab. & Est.. & Trab. \\
\hline Alv.do Sul & 17 & 144 & 140 & 314 & 20 & 46 & 140 & 798 & 12 & 13 & 90 & 202 \\
\hline Apucarana & 1.636 & 14.555 & 2.475 & 5.859 & 421 & 1.602 & 2.366 & 10.030 & 307 & 1.320 & 305 & 562 \\
\hline Arapongas & 802 & 16.958 & 2.158 & 6.080 & 411 & 1.066 & 1.574 & 8.205 & 217 & 528 & 206 & 924 \\
\hline Assaí & 71 & 1.331 & 273 & 561 & 26 & 61 & 273 & 925 & 14 & 8 & 109 & 139 \\
\hline B. V. Paraiso & 96 & 1.082 & 304 & 436 & 32 & 116 & 259 & 953 & 16 & 12 & 95 & 190 \\
\hline Cambé & 649 & 8.048 & 1.522 & 3.391 & 271 & 1.371 & 1.090 & 5.214 & 192 & 694 & 243 & 526 \\
\hline Ibiporã & 276 & 3.297 & 741 & 1.554 & 115 & 449 & 655 & 3.686 & 74 & 397 & 109 & 337 \\
\hline Jataizinho & 47 & 504 & 170 & 175 & 18 & 76 & 151 & 781 & 6 & 12 & 65 & 108 \\
\hline Londrina & 3.238 & 28.305 & 13.533 & 33.834 & 2.758 & 6.273 & 14.094 & 75.736 & 1.675 & 9.673 & 952 & 3.054 \\
\hline Prim. Maio & 38 & 248 & 167 & 260 & 18 & 49 & 143 & 1.277 & 9 & 17 & 95 & 145 \\
\hline Rolândia & 580 & 10.155 & 1.336 & 2.704 & 283 & 1.187 & 1.090 & 4.323 & 140 & 338 & 250 & 1.210 \\
\hline Sertanópolis & 132 & 892 & 372 & 686 & 47 & 340 & 305 & 1.404 & 26 & 37 & 186 & 384 \\
\hline Tamarana & 30 & 318 & 218 & 169 & 22 & 72 & 158 & 591 & 15 & 53 & 76 & 198 \\
\hline Jaguapitã & 52 & 2.906 & 107 & 376 & 5 & 149 & 78 & 720 & 10 & 13 & 111 & 302 \\
\hline Pitangueiras & 8 & 48 & 16 & 36 & 3 & 14 & 18 & 192 & 3 & 5 & 23 & 124 \\
\hline Sabáudia & 35 & 393 & 40 & 310 & 26 & 114 & 69 & 1.129 & 2 & 8 & 65 & 247 \\
\hline
\end{tabular}

Fonte: Brasil. MTE/RAIS, 2009.

Org.: Fresca, T. M.

Dentre as 16 cidades, 7 tinham predomínio do emprego industrial, a começar por Apucarana com 42,89\% do total, sendo uma cidade especializada na produção industrial confeccionista de bonés, representando cerca de $70 \%$ da produção nacional (VIETRO, 2011). Em Arapongas o setor industrial representava 50,22\% do total de empregos, configurando-se em um dos quatro principais polos moveleiros do país (FRESCA, 2009), enquanto Cambé representava 41,82\%, caracterizado por ser um setor industrial diversificado, mas com presença de grandes empresas locais e transferidas de outras regiões metropolitanas, particularmente São Paulo a partir de meados dos anos de 1990. Em Rolândia o emprego industrial representava 50,98\%, dos quais, o de maior destaque era o alimentício, particularmente nas agroindústrias avícolas. Em Assaí os empregos industriais representavam $44 \%$ do total, cujo setor é o metal-mecânico, onde tem-se tanto fornecedores para a Atlas-Schindler, multinacional instalada em Londrina produzindo elevadores, esteiras e escadas rolantes, como indústrias mecânicas produzindo partes e componentes de equipamentos pesados (ALMEIDA, 2011). Bela Vista do Paraíso, outra pequena cidade da RML, o setor representou 38,79\% do total de 
empregos, dos quais destaca-se a indústria mecânica. Em Jaguapitã os empregos industriais representaram $65 \%$ do total; coloca-se ainda como uma cidade especializada na produção de mesas para bilhar (VEIGA, 2007), controlando parcela importante do mercado consumidor do Sul do Brasil, porém a maior parte dos empregos está na indústria alimentícia, particularmente nas agroindústrias avícolas. Em Ibiporã, embora o setor industrial seja o segundo de maior geração de empregos (33,91\% dos empregos), nota-se tratar de um setor diversificado, destacando-se o metalúrgico com grande concentração na produção de furgões de diversos tipos para caminhões e juntas para diversos usos e o químico de produtos farmacêuticos, além de tintas. Londrina, diferente das demais, apresenta o maior número de empregos em termos absolutos, mas percentualmente representava $18 \%$ de empregos no setor industrial. No entanto, este setor é diversificado e complexo, apresentando desde indústrias confeccionista ( a maior geradora de empregos com 7.438 empregos), alimentícia (5.154 empregos), mas inclui segmentos mais dinâmicos como mecânica, transporte e material elétrico, dentre outros; marcado também pela presença de grandes empresas de capital nacional e internacional. A dinâmica industrial desta área pode ser melhor entendida a partir de Bragueto (2007), que analisou o aglomerado urbano-industrial de Londrina, constituído por Apucarana, Arapongas, Rolândia, Cambé, Ibiporã e Londrina, em razão de concentrar o maior número de trabalhadores e estabelecimentos industriais.

A partir do quadro, verifica-se ainda que Alvorada do Sul, Jataizinho, Primeiro de Maio, Sertanópolis, Tamarana, Pitangueiras e Sabáudia, apresentam o predomínio do emprego nos serviços, todas caracterizadas por serem pequenas cidades, nas quais os serviços na administração pública direta e autarquias tinham importante peso: $24,5 \%$ do total de empregos em Alvorada do Sul; 25,1\% em Jataizinho; 18,03\% em Primeiro de Maio; 28,26\% em Tamarana; 28,26\% em Tamarana e 40,5\% em Pitangueiras. Em Ibiporã este setor tem a maior participação na geração de empregos, representando 37,92\%, mas os empregos na administração pública participavam com 13,62\%. Diferente era a situação em Londrina, onde os serviços representaram 48,27\% do total dos empregos em 2010, com pequena participação daqueles na administração direta e autarquias (4,49\% do total), demonstrando que a maior parte dos empregos vincula-se a outras atividades prestadoras de serviços; o segundo setor de maior geração de empregos era o comércio varejista representando $21,56 \%$ do total.

Geo UERJ - Ano 14, no. 23, v. 1, $1^{\circ}$ semestre de 2012 p. 167-191

ISSN: 1415-7543 E-ISSN: 1981-9021

http://www.e-publicacoes.uerj.br/index.php/geouerj 
Por outro lado, a agricultura, o extrativismo e a criação de animais tinham destaque em termos absolutos apenas em Londrina, Arapongas e Rolândia, mas com participação relativa importante apenas nesta última com 10,25\% do total de empregos. Em termos relativos há que se destacar que em Alvorada do Sul representava 13,3\% e em Tamarana $14,13 \%$ do total de empregos.

O comércio atacadista tinha representação no total de empregos em apenas algumas cidades, com destaque para Cambé cujo total atingia 7,12\% do total; em Rolândia com 5,95\%; Arapongas com 4,72 e Apucarana com 3,15\%, enquanto Londrina, que em termos absolutos tinha o maior número, representando apenas 3,99\% do total. O comércio varejista, em termos absolutos tem maior importância em Londrina, Arapongas, Apucarana, Cambé, Rolândia e Ibiporã, mas percentualmente oscilam bastante; a menor representação deste segmento estava em Jataizinho com 10,56\% do total de empregos, seguido por Tamarana com 12,06\%; as maiores em Londrina com $21,56 \%$ e Alvorada do sul com 20,69\%; as demais oscilavam entre $13 \%$ e $18 \%$.

A construção civil, uma atividade de forte geração de empregos, principalmente no contexto do PAC com forte redução nas taxas de juros para aquisição de habitação, também não tem destaque nas cidades em tela. Apenas em Londrina representou $6,16 \%$ do total de empregos em 2010, mas ressalte-se que há forte informalidade neste segmento da economia.

Desta maneira, as maiores gerações de empregos estão nas cidades de Londrina, Apucarana, Arapongas, Rolândia, Cambé, Ibiporã, Sertanópolis e Assaí, que exceto as duas últimas, são as maiores em termos populacionais. Mas chama-se a atenção para o fato de que em Rolândia a geração de empregos é muito maior comparativamente à Cambé e Ibiporã em termos de representação absoluta e relativa sobre a população total. Isso se deve em parte ao importante setor industrial na primeira. Nas demais, caracterizadas por serem pequenas cidades, o emprego é relativamente menor, muito vinculado aos serviços, particularmente à administração pública. Por outro lado, verifica-se que Londrina, enquanto sede desta região metropolitana, tem suas atividades predominantemente nos serviços e comércio varejista.

\section{Uma interpretação dos deslocamentos pendulares: considerações finais}


Com base nos dados apresentados, estaríamos diante de processos de repetição de um padrão de formação de regiões metropolitanas que vem ocorrendo desde meados do século XX no Brasil? Em parte os dados apresentados revelam a formação da região metropolitana a partir da conurbação/aglomeração desde o início dos anos de 1980, com maior articulação entre as cidades via transporte metropolitano a partir do final da referida década. Nas décadas seguintes intensificou a formação da aglomeração urbana e das articulações materiais e imateriais entre os municípios que viriam a formar a região metropolitana, mas com destaque para aqueles localizados ao longo da BR 369. No entanto, dentre os deslocamentos pendulares, estes não se realizam predominantemente para a cidade principal visando empregos industriais. Este elemento é importante porque não reproduz processos que ocorreram em outras metrópoles brasileiras, denotando outros percursos na formação e consolidação de Londrina como cidade sede de uma região metropolitana.

Londrina nunca teve o predomínio de sua geração de empregos, impostos, participação no valor adicionado, dentre outros, na indústria. Desde sua gênese esteve muito mais voltada ao comércio e prestação de serviços, embora nela se fizesse presente uma produção industrial desde os anos de 1950/1960 com destaque para setor alimentício, químico, dentre outros. Assim não se pode falar da formação da região metropolitana correlacionada à produção industrial na cidade principal. Da mesma forma, o avanço e consolidação desta região, não vincula-se ao processo de desconcentração da indústria da cidade principal para as cidades mais próximas, em um processo que foi recorrente para várias metrópoles brasileiras.

Até meados dos anos de 1990, a industrialização presente nas cidades da RML, Arapongas e Apucarana era fruto da ação do capital local e regional. Tratava-se de um processo de transferência de capital agrário e urbano - oriundo da pequena produção mercantil - para atividades industriais, cuja gênese ocorreu a partir dos anos de 1970. Inclusive como um processo de substituição de atividades a partir das transformações agrárias em direção à implantação de diversos agronegócios no norte do Paraná. Industrialização essa cuja dinâmica foi capaz de colocar alguns ramos industriais no cenário nacional com controle de parcela importante do mercado consumidor.

A partir dos anos de 1990, a RML foi afetada diretamente pelo denominado processo de reestruturação produtiva. Trata-se dentre outros, de uma estratégia adotada por várias 
empresas de capital nacional e internacional presentes no Brasil para enfrentamento das repercussões da crise econômica iniciada a partir do início dos anos de 1990, quando da abertura do mercado consumidor nacional aos produtos e indústrias internacionais que afetaram muitos segmentos. Para manterem-se no mercado e recuperar posições, a transferência industrial configurou-se em rebaixamento de custos: mão-de-obra, terreno, transporte, serviços especializados, acesso a energia, localização privilegiada em relação aos principais mercados consumidores nacionais - Grande São Paulo, interior de São Paulo, países do Mercosul, etc. - presença de infraestrutura, acessibilidade, dentre outros. Neste percurso muitas escolhas recaíram nas cidades de Cambé, Ibiporã, Rolândia, Assaí e Londrina, que apresenta a maior geração de empregos.

Acrescente-se ainda a "guerra fiscal" praticada entre as municipalidades, particularmente Cambé, que ofertou algumas condições infraestruturais mais vantajosas para as indústrias que realizaram o processo de transferência de suas plantas industriais ao longo dos anos de 1990. Além deste fator, acrescente-se ainda a questão dos terrenos livres para a implantação das unidades produtivas nas cidades vizinhas a Londrina, fator este relativamente limitante na última. Isto ocorre em razão da cidade de Londrina ter passado por grande expansão físico-territorial em todas as direções, até atingir determinadas condições geomorfológicas que dificultam a instalação de unidades industriais. Em outras palavras, ao sul da atual malha urbana, o relevo apresenta declividade bastante acentuada já que está nos limites da divisão entre o Segundo e o Terceiro Planalto, enquanto a leste e oeste há relativa ausência de áreas livres para tal fim, mediante aglomeração com Cambé e Ibiporã. Ao norte, a expansão da malha urbana prossegue intensamente. Estes elementos provocam aumento do preço da terra e acabam por criar condições muito mais viáveis para a instalação industrial nas cidades da aglomeração urbana e ao mesmo tempo, desfrutam de serviços especializados, infraestrutura e consumo diversificado em Londrina. Neste contexto tem-se a transferência de unidades produtivas industriais de capital nacional e internacional para cidades da RML, algumas das quais com suas fornecedoras (FRESCA, 2004).

Dessa maneira argumenta-se que a criação e a consolidação da RML, acrescida de Arapongas e Apucarana, apoia -se em uma divisão do trabalho complexa, onde é nítido que a cidade principal concentrou principalmente as atividades comerciais e prestadoras de serviços, enquanto a produção industrial tem presença importante (em termos de 
geração de empregos, mas no PIB não); nos demais municípios a produção industrial tem muito maior representação em termos absolutos e relativos conforme exposto anteriormente.

Neste conjunto, os deslocamentos pendulares são complexos porque não são unidirecionais para a cidade principal; porque envolvem diferentes objetivos, passando pelo trabalho, consumo de bens e serviços, pela infraestrutura; porque demonstram diversidade em termos de fluxos numéricos entre as cidades integrantes da RML, Arapongas e Apucarana, desde aqueles muito intensos até aqueles com fraqueza de deslocamentos. Esta aproximação ao entendimento dos deslocamentos pendulares suscita por certo, inúmeras pesquisas como desvendamento dos fluxos efetivamente para o trabalho, para obtenção de serviços e consumo; suscita ainda avançar na compreensão dos deslocamentos que se realizam entre as diferentes cidades que não sejam a principal; além de compreender quem são as pessoas que se deslocam.

\section{Referências}

ALMEIDA, Adriano Pereira. A especialização metalmecânica e as transformações espaciais em Assaí - PR. 2011. Dissertação (Mestrado em Geografia) - Universidade Estadual de Londrina, Londrina.

ANTICO, Cláudia. Deslocamentos pendulares nos espaços sub-regionais da Região Metropolitana de São Paulo. In: ENCONTRO NACIONAL DE ESTUDOS POPULACIONAIS, 14, 2004, Caxambu. Anais... Campinas: ABEP, 2004. BAENINGER, Rosana A.; OJIMA, Ricardo. Novas territorialidades e a sociedade de risco: evidências empíricas e desafios teóricos para a compreensão dos novos espaços da migração. Papeles de Población, Toluca: Centro de Investigacion y Estudios Avanzados de La Poblacion, v.14, n.58, p.141-154, 2008.

BEAUJEAU-GARNIER, Jacqueline. Geografia urbana. Lisboa: Fundação Calouste Gulbenkian, 1980.

BERRY, Brian; HORTON, Frank. Problems of defining the metropolis. In:

Geographic perspective on urban systems: with integrated reading. New Jersey: Prentice Hall Inc/Englewood Cliffs, 1970, p. 250-275.

BRAGUETO, Cláudio R. O aglomerado urbano-industrial de Londrina: sua constituição e dinâmica industrial. 2007. Tese (Doutorado em Geografia) - USP, São Paulo.

BRASIL. Ministério do Trabalho e Emprego. Base estatística RAIS: relação anual de informações sociais: RAISESTAB/RAISTRAB, 2009. Brasília, 2009, CDROM. DEPARTAMENTO DE ESTRADAS DE RODAGEM. PARANÁ. Transporte intermunicipal de passageiros: movimento de passageiros por linha: Cambé, Ibiporã, Jataizinho, Assaí, Bela Vista do Paraíso, Primeiro de Maio, Sertanópolis, Tamarana, Rolândia, Londrina, Apucarana. dez./2009 a nov./2010. Curitiba, 2011.

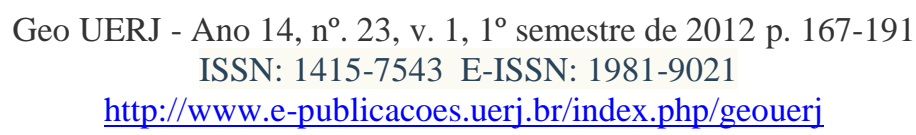


FITZSIMMONS, James; RATICLIFFE, Michael. Metropolitan area standards review: new definitions for census 2000. Disponível em: <www.iussp.prg/menbers/restricted/publications >. Acesso em 08 de outubro de 2010. FRESCA, Tânia Maria. Industrialização no Norte do Paraná na década de 1990: transferência industrial e estratégias de crescimento. Ciência Geográfica, Bauru, v. 10, p. 195-206, 2004.

FRESCA, Tânia Maria. Rede urbana, níveis de centralidade e produção industrial: perspectivas para um debate. ENCUENTRO DE GEOGRAFOS DE AMÉRICA LATINA, 12, 2009, Montevideo. Anais... Montevideo, 2009.

FRESCA, Tânia Maria. As dimensões espaciais de Londrina - PR. Relatório Final de Atividades Pós-Doutorais. Rio de Janeiro: UFRJ, 2011. Inédito.

GALVÃO, Marília V. et. al.. Áreas de pesquisa para determinação de áreas metropolitanas. Revista Brasileira de Geografia, Rio de Janeiro, v. 31, n. 4, 1969, p. 53-128.

IBGE. Censo demográfico 2000: migração e deslocamentos: resultados da amostra. Rio de Janeiro: IBGE, 2000. CD-ROM.

IBGE. Primeiros resultados do Censo de 2010. Disponível em: < http://www.ibge.gov.br/home/estatistica/populacao/censo2010/tabelas_pdf/total_popula cao_parana.pdf>. Acesso em fevereiro de 2012.

JARDIM, Antonio Ponte; ERVATTI, Leila Regina. Migração pendular intrametropolitana no Rio de Janeiro: a condição de renda das pessoas que trabalham ou estudam fora do município de residência em 1980 e 2000. In: ENCONTRO

NACIONAL DE ESTUDOS POPULACIONAIS, 15., 2006, Caxambu. Anais... Belo Horizonte: ABEP, 2006.

JARDIM, Antonio Ponte. Reflexões sobre a mobilidade pendular. In: OLIVEIRA, Luiz Antonio P.; OLIVEIRA, Antonio Tadeu Ribeiro. (org). Reflexões sobre os deslocamentos populacionais no Brasil. Rio de Janeiro: IBGE, 2011. p. 58-70. MOURA, Rosa; CASTELLO-BRANCO, Maria Luiza; FIRKOWSKI, Olga Lúcia C. Freitas. Movimento pendular e perspectivas de pesquisas em aglomerados urbanos. São Paulo em Perspectiva, São Paulo: SEADE, v.19, n.4, p.121-133, out./dez. 2005. OJIMA, Ricardo. Fronteiras metropolitanas: um olhar a partir dos movimentos pendulares. Revista Paranaense de Desenvolvimento, Curitiba, n.121, p.109-126, jul./dez. 2011.

OLIVEIRA, Luiz Antonio P. ; OLIVEIRA, Antonio Tadeu Ribeiro. (org). Reflexões sobre os deslocamentos populacionais no Brasil. Rio de Janeiro: IBGE, 2011. OLIVEIRA, Antonio Tadeu Ribeiro. Algumas abordagens teóricas a respeito de fenômeno migratório. In: OLIVEIRA, Luiz Antonio P. ; OLIVEIRA, Antonio Tadeu Ribeiro. (org). Reflexões sobre os deslocamentos populacionais no Brasil. Rio de Janeiro: IBGE, 2011. p. 11-27.

RIBEIRO, L. C. DE Q. Hierarquização e identificação dos espaços urbanos. Rio de Janeiro: Letra Capital: Observatório das Metrópoles, 2009.

ROCHEFORT, Michel. Redes e sistemas: ensinando sobre o urbano e a rede. São Paulo: Hucitec, 1998.

SANTOS, Milton. A urbanização brasileira. São Paulo: Hucitec, 1993.

SINGER, Paul. Migrações internas: considerações sobre o seu estudo. In: SINGER, Paul. Economia política da urbanização. São Paulo: Brasiliense, 1985.

VEIGA, Léia Aparecida. Jaguapitã-PR: pequena cidade da rede urbana norteparanaense especializada na produção industrial de mesas para bilhar. 2007.

Geo UERJ - Ano 14, no. 23, v. 1, $1^{\circ}$ semestre de 2012 p. 167-191

ISSN: 1415-7543 E-ISSN: 1981-9021

http://www.e-publicacoes.uerj.br/index.php/geouerj 
Dissertação (Mestrado em Geografia Meio Ambiente e Desenvolvimento) Universidade Estadual de Londrina. Londrina - PR.

VIETRO, Anderson de Freitas. A indústria confeccionista no Norte do Paraná. 2011. Dissertação (Mestrado em Geografia) - UFSC, Florianópolis.

Artigo encaminhado para publicação em junho de 2012.

Artigo aceito para publicação em julho de 2012. 